\title{
PENGARUH KEPRIBADIAN DAN MOTIVASI TERHADAP KINERJA KARYAWAN PT BPR FAJAR ARTHA MAKMUR
}

\author{
${ }^{1)}$ Yasnimar Ilyas, ${ }^{2)}$ Raudhatul Zannah \\ ${ }^{1)}$ Dosen Program Studi Manajemen, STIE Dewantara \\ J1. Raya Pemda Bojong Depok Baru III, Karadenan, Cibinong, Bogor, Jawa Barat 16913, Indonesia \\ Email: yasnimar.ilyas@ dewantara.ac.id \\ ${ }^{2)}$ Alumni Program Studi Manajemen, STIE Dewantara \\ Jl. Raya Pemda Bojong Depok Baru III, Karadenan, Cibinong, Bogor, Jawa Barat 16913, Indonesia \\ Email: raudhatulzannah598@gmail.com
}

\begin{abstract}
The purpose of this study was to determine the effect of personality and motivation on the performance of PT BPR Fajar Artha Makmur employees. In this study the object is a permanent employee or contract of PT BPR Fajar Artha Makmur. The population in this study were all employees working at the office of PT BPR Fajar Artha Makmur in the operational field of 50 people. The samples taken were 50 samples. Data analysis uses multiple linear regression. The results of the study showed discipline at PT. BPR Fajar Artha Makmur has gone very well. This can be seen based on the answers of 50 respondents, with an average number of 3.82. Motivation at PT. BPR Fajar Artha Makmur has gone quite well. This can be seen based on the answers of 50 respondents, with an average number of 3.02. Employee performance at PT. BPR Fajar Artha Makmur has gone well. This is seen based on the answers of the respondents as many as 50 people, with an average number of 3.05. Based on the results of data analysis using statistical methods, namely the correlation coefficient that is equal to 0.797, and according to the provisions of the author, it can be concluded that discipline and motivation have a strong level of relationship strength to employee performance variables, this shows that discipline and motivation have a strong influence on performance employees at PT. BPR Fajar Artha Makmur.
\end{abstract}

Keyword: Personality, Motivation, Performance of Employees of PT BPR Fajar Artha Makmur.

\begin{abstract}
ABSTRAK
Tujuan penelitian ini untuk mengetahui pengaruh kepribadian dan motivasi terhadap kinerja karyawan PT BPR Fajar Artha Makmur. Dalam penelitian ini objeknya adalah karyawan tetap maupun kontrak PT BPR Fajar Artha Makmur. Populasi dalam penelitian ini adalah seluruh karyawan yang bekerja pada kantor PT BPR Fajar Artha Makmur pada bidang operasional yang berjumlah 50 orang. Sampe yang diambil adalah 50 sampel. Analisa sata menggunakan regresi linear berganda. Hasil penelitian menunjukkan disiplin pada PT. BPR Fajar Artha Makmur telah berjalan sangat baik. Hal ini terlihat berdasarkan hasil jawaban dari responden sebanyak 50 orang, dengan jumlah rata-rata sebesar 3,82. Motivasi pada PT. BPR Fajar Artha Makmur telah berjalan cukup baik. Hal ini terlihat berdasarkan hasil jawaban dari responden sebanyak 50 orang, dengan jumlah rata-rata sebesar 3,02. Kinerja pegawai pada PT. BPR Fajar Artha Makmur telah berjalan dengan baik. Hal ini terlihat berdasarkan jawaban dari responden sebanyak 50 orang, dengan jumlah rata-rata 3,05. Berdasarkan hasil analisis data dengan menggunakan metode statistik yaitu koefisien korelasi yaitu sebesar 0,797, dan sesuai dengan ketentuan penulis, maka dapat disimpulkan bahwa kedisiplinan dan motivasi memiliki tingkat kekuatan hubungan yang kuat terhadap variabel kinerja karyawan, hal ini menunjukkan bahwa kedisiplinan dan motivasi berpengaruh kuat terhadap kinerja karyawan pada PT. BPR Fajar Artha Makmur.
\end{abstract}

Kata kunci: Kepribadian, Motivasi , Kinerja Karyawan PT BPR Fajar Artha Makmur. 


\section{PENDAHULUAN}

Sumber daya manusia merupakan faktor sentral dalam suatu organisasi. Apabila dibandingkan dengan sumber daya lainnya, sumber daya manusia adalah sumber daya yang paling unik, karena sumber daya manusia merupakan hal terpenting dalam suatu organisasi untuk mengatur segala kegiatan dalam organisasi. Untuk menjalankan sumber daya manusia dibutuhkan tenaga dan bantuan orang lain. Karyawan merupakan sumber daya manusia yang sangat penting dalam kegiatan organisasi karena mereka memiliki pengetahuan dan kemampuan yang dapat mendukung untuk mencapai kinerja yang baik. Tenaga kerja atau karyawan merupakan sumber daya yang paling berharga didalam organisasi. Tanpa adanya tenaga kerja atau karyawan yang berkualitas mustahil tujuan organisasi dapat tercapai dengan baik.

Dalam upaya memperbaiki kinerja para karyawan, terdapat fenomena yang menjadi kendala yaitu perilaku karyawan yang kurang maksimal dalam mematuhi peraturan yang telah ditetapkan oleh organisasi dan tugas-tugas yang telah menjadi tanggung jawabnya. Dalam keadaan tersebut diperlukan usaha dari karyawan dan pimpinan. Usaha yang mampu dilakukan oleh karyawan adalah dengan menyadari tugas dan kewajibannya yang telah ditetapkan, memperbaiki perilaku yang kurang baik agar lebih taat kepada aturan yang telah ditetapkan agar dapat meningkatkan kinerjanya menjadi lebih maksimal. Pemimpin harus bisa melihat keadaan lingkungan organisasi dan keadaan karyawannya agar kinerja para karyawan lebih baik. Pemimpin juga harus bisa memberikan contoh yang baik kepada bawahannya untuk memiliki sikap yang diluar tuntutan organisasi yang dilakukan berdasarkan keinginan sendiri dan tidak mengharapkan imbalan dari siapa pun. Sikap ini seperti, dengan menolong rekan kerja, peduli terhadap organisasi tanpa harus menunggu perintah, memiliki sikap yang bersahabat terhadap rekan kerja. Dengan sikap tersebut secara tidak langsung akan berdampak pada peningkatan kinerja dan peningkatan nilai organisasi. Berdasarkan uraian diatas, maka peneliti tertarik untuk melakukan penelitian dengan judul: "Pengaruh Kepribadian dan Motivasi Terhadap Kinerja Karyawan PT BPR Fajar Artha Makmur"

\subsection{Rumusan Masalah}

Berdasarkan latar belakang yang telah disampaikan di atas, maka terdapat beberapa masalah yang perlu dikaji dalam penelitian ini. Sesuai uraian tersebut, maka penulis merumuskan masalah sebagai berikut :

1. Bagaimana pengaruh kepribadian terhadap kinerja karyawan di PT BPR Fajar Artha Makmur?

2. Bagaimana pengaruh motivasi terhadap kinerja karyawan PT BPR Fajar Artha Makmur?

3. Bagaimana pengaruh kepribadian dan motivasi secara simultan terhadap kinerja karyawan PT BPR Fajar Artha Makmur?

\subsection{Tujuan}

Tujuan dari penelitian ini adalah:

1. Mengetahui pengaruh kepribadian terhadap kinerja karyawan PT BPR Fajar Artha Makmur

2. Mengetahui pengaruh motivasi terhadap kinerja PT BPR Fajar Artha Makmur

3. Mengetahui pengaruh kepribadian dan motivasi secara simultan terhadap kinerja karyawan PT BPR Fajar Artha Makmur.

\section{TINJAUAN PUSTAKA}

\subsection{Pengertian Kepribadian}

Kreitner dan Kinicki (2010:133) mendefinisikan kepribadian atau 
personality adalah kombinasi karakteritik fisik dan mental yang stabil yang memberikan identitas individualnya. Karakteristik atau ciri atau sifat ini termasuk bagaimana orang melihat, berpikir, bertindak dan merasakan, yang merupakan produk interaksi genetik dan pengaruh lingkungan.

Pendapat lain mengemukakan bahwa kepribadian adalah pola yang relatif bertahan lama tentang pemikiran, emosi dan perilaku yang menunjukkan karakteristik orang, sejalan dengan proses pskol ogis di belakang karakteristik tersebut (McShane dan Von Glinow, 2010:38).

Sementara itu Robbins dan Judge (2010:169) menyatakan bahwa kepribadian adalah organisasi dinamis dari sistem psikologis dalam diri individu yang menentukan penyesuaian uniknya pada lingkungannya. Sedangkan menurut Colquitt, Lepine dan Wesson (2011:294) kepribadian menunjukkan struktur dan kecendrungan dalam diri orang yang menjelaskan pola karakteristik mereka dalam pemikiran, emosi, dan perilaku. Faktor yang mempengaruhi kepribadian terdiri dari unsur-unsur sebagai berikut:

1. Heredity

Heredity atau keturunan merupakan faktor yang ditentukan oleh konsepsi. Ketinggian fisik, kemenarikan wajah, gender, temperamen, komposisi otot dan refleks, tingkat energi, dan ritme biologis umumnya dipertimbangkan untuk sebagian atau seluruhnya dipengaruhi oleh orang tua, dengan biologis, fisiologis dan melekat dengan susunan psikologi.

\section{Environment}

Faktor lingkungan mempunyai peranan penting dalam membentuk kepribadian. Faktor yang menggunakan tekanan pada pembentukan kepribadian adalah budaya dimana kita tumbuh, pada pembentukan kondisi awal, norma diantara keluarga, teman, dan kelompok sosial, dan pengaruh lain menurut pengalaman kita.

\section{Situation}

Situasi mempengaruhi Hereity dan Environment pada kepribadian. Kepribadian individu meskipun biasanya stabil dan konsisten, dapat berubah dalam situasi tertentu.

\section{Life Experience}

Pengalaman hidup yang dilalui seseorang sejak kecil, menjadi dewasa, dan sampai mencapai umur lanjut akan mempengaruhi kepribadian seseorang.

\subsection{Pengertian Motivasi}

Robbert Heller (1998:6) menyatakan bahwa motivasi adalah keinginan untuk bertindak. Motivasi kerja adalah hasil dari kumpulan kekuatan internal dan eksternal yang menyebabkan pekerja memilih jalan bertindak yang sesuai dan menggunakan perilaku tertentu. Idealnya para perilaku ini diarahkan pada pencapaian tujuan organisasi (Newstrom, 2011:109).

Robbins dan Judge, McShane dan Von Glinow (2010:132) memberikan defenisi motivasi sebagai kekuatan dalam diri orang yang mempengaruhi arah (direction), intensitas (intensity), dan ketekunan (persistance) perilaku sukarela. Pekerja yang termotivasi berkeinginan menggunakan tingkat usaha tertentu. (persistance), terhadap tujuan tertentu (direction). Motivasi merupakan salah satu dari empat pendorong perilaku dan kinerja individual.

Sedangkan Colquitt, LePine, dan Wesson (2011:179) memberikan defenisi motivasi sebagai sekumpulan kekuatan energitik yang dimulai baik dari dalam maupun diluar pekerja, dimulai dari usaha yang berkaitan dengan pekerjaan, dan mempertimbangkan arah, intensitas, dan ketekunannya.

Sementara itu Newstrom (2011) mengemukakan bahwa sebagai indikator motivasi adalah: 
1. Engagement (Perjanjian)

Merupakan janji pekerja untuk menunjukkan tingkat antusiasme, inisiatif, dan usaha untuk meneruskan.

2. Commitment (Komitmen)

Adalah suatu tingkatan dimana pekerja mengikat dengan organisasi dan menunjukkan tindakan organizational citizenship.

3. Satisfaction (Kepuasan)

Merupakan refleksi pemenuhan kontrak psikologis dan memenuhi harapan ditempat kerja.

4. Turnover (Pergantian)

Merupakan kehilangan pekerja yang dihargai.

\subsection{Pengertian Kinerja}

Menurut Anwar Prabu Mangkunegara (2009) kinerja sebagai "hasil kerja secara kualitas dan kuantitas yang dicapai seorang pegawai dalam melaksanakan tugasnya sesuai dengan tanggung jawab yang diberikan kepadanya". Sedangkan menurut Nawawi.H.Hadari, yang dimaksud dengan kinerja adalah: "hasil dari suatu pekerjaan, baik yang bersifat fisik/mental maupuun non fisik/non mental". Sementara itu menurut Bernaden dan Russel, sebagaimana dikutif oleh Gomes, Faustino Cardoso Gomes(2000), kinerja diartikan sebagai : "catatan outcome yang dihasilkan dari fungsi suatu pekerjaan tertentu atau kegiatan suatu karyawan selama suatu periode tertentu".

Menurut Gibson (2007) mendefinikan kinerja sebagai hasil dari pekerjaan yang terkait dengan tujuan organisasi seperti kualitas, efesiensi dan kriteria efektifitas kerja lainnya. Kinerja pada dasarnya adalah apa yang dilakukan atau tidak dilakukan oleh karyawan. Kinerja merupakan hal yang sangat penting dalam suatu perusahaan untuk mencapai tujuannya. Kinerja dapat berjalan baik apabila karyawan mendapatkan gaji sesuai dengan harapan, mendapatkan pelatihan dan pengembangan, lingkungan kerja yang kondusif, mendapat perlakuan yang sama, penempatan karyawan sesuai dengan keahliannya, serta mendapatkan bantuan perencanaan karir, serta terdapat ummpan balik dari perusahaan.

Menurut Mangkunegara (2009) bahwa karakteristik orang yang mempunyai kinerja tinggi adalah sebagai berikut:

a. Memiliki tanggung jawab pribadi yang tinggi.

b. Berani mengambil dan menanggung resiko yang dihadapi.

c. Memiliki tujuan yang realistis.

d. Memiliki rencana kerja yang menyeluruh dan berjuang untuk merealisasi tujuannya.

e. Memanfaatkan umpan balik (feedback) yang konkrit dalam seluruh kegiatan kerja yang dilakukannya.

f. Mencari kesempatan untuk merealisasikan rencana yang telah diprogramkan.

Untuk mengukur kinerja dapat digunakan beberapa ukuran kinerja. Beberapa ukuran kinerja yang meliputi: kuantitas kerja, kualitas kerja, pengetahuan tentang pekerjaan, kemampuan mengemukakan pendapat, pengambilan keputusan, perencanaan kerja dan daerah organisasi kerja. Ukuran prestasi yang lebih disederhana terdapat 3 (tiga) kriteria untuk mengukur kinerja. Yang pertama kuantitas kerja, yaitu jumlah yang harus dikerjakan. Kedua kualitas kerja yaitu mutu yang dihasilankan, dan yang ketiga ketepatan waktu, yaitu kesesuaiannya dengan waktu yang telah ditetapkan. Menurut Mangkunegara (2009) kinerja karyawan dapat diukur melalui indikator-indikator sebagai berikut:

a. Kuantitas kerja

Yaitu jumlah kerja yang dilakukan suatu periode yang ditentukan.

b. Kualitas kerja 
Kualitas kerja yang dicapai berdasarkan syarat-syarat kesesuaian dan kesiapannya.

c. Kreatifitas kerja

Keaslian gagasan-gagasan yang dimunculkan dan tindakan-tindakan untuk menyelesaikan suatu pekerjaan secara cepat dan efesien (tepat guna).

d. Pengetahuan kerja

Luasnya pengetahuan mengenai pekerjaan dan keterampilan.

\subsection{Definisi Operasional}

Tabel 2.2. Ringkasan pengukuran setiap variabel dan dimensi dalam indikator disajikan pada:

\begin{tabular}{|c|c|c|c|}
\hline Variabel & Indikator & Instrumen & Skala \\
\hline \multirow{5}{*}{$\begin{array}{c}\text { Kepribadia } \\
\text { n } \\
\text { karyawan } \\
\text { (Sumber : } \\
\text { Kreitner } \\
\text { dan } \\
\text { Kinicki, } \\
\text { 2010) }\end{array}$} & (Keterbukaan) & $\begin{array}{c}\text { Senang } \\
\text { bergaul, } \\
\text { bekerja } \\
\text { dalam } \\
\text { kelompok, } \\
\text { dan berada } \\
\text { dalam } \\
\text { keramaian }\end{array}$ & Likert \\
\hline & $\begin{array}{c}\text { Agreeablenes } \\
s \\
\text { (Keramahan) }\end{array}$ & $\begin{array}{c}\text { Ramah } \\
\text { tamah, suka } \\
\text { membantu, } \\
\text { pemaaf, dan } \\
\text { penyayang }\end{array}$ & Likert \\
\hline & $\begin{array}{c}\text { Conscientious } \\
\text { ness } \\
\text { (Kesungguha } \\
\text { n hati) }\end{array}$ & $\begin{array}{c}\text { Disiplin dan } \\
\text { berhati-hati } \\
\text { dalam } \\
\text { bekerja }\end{array}$ & Likert \\
\hline & $\begin{array}{l}\text { Emotional } \\
\text { Stability } \\
\text { (Stabilitas } \\
\text { emosional) }\end{array}$ & $\begin{array}{c}\text { Gangguan } \\
\text { emosi }\end{array}$ & Likert \\
\hline & $\begin{array}{c}\text { Openness to } \\
\text { Experience } \\
\text { (pengalaman) }\end{array}$ & $\begin{array}{c}\text { Keterbukaan } \\
\text { terhadap } \\
\text { ide-ide baru, } \\
\text { mudah } \\
\text { bertoleransi } \\
\text { terhadap } \\
\text { perubahan } \\
\text { dan senang } \\
\text { dengan } \\
\text { pengalaman- } \\
\text { pengalaman } \\
\text { baru. }\end{array}$ & Likert \\
\hline
\end{tabular}

\begin{tabular}{|c|c|c|c|}
\hline Variabel & Indikator & Instrumen & Skala \\
\hline \multirow{4}{*}{$\begin{array}{c}\text { Motivasi } \\
\text { Karyawan } \\
\text { (Sumber: } \\
\text { Newstrom } \\
\text {,2011) }\end{array}$} & $\begin{array}{c}\text { Engagement } \\
\text { (perjanjian) }\end{array}$ & $\begin{array}{c}\text { Janji pekerja } \\
\text { untuk } \\
\text { menunjukkan } \\
\text { tingkat } \\
\text { antusiasme, } \\
\text { inisiatif, dan } \\
\text { usaha untuk } \\
\text { meneruskan. }\end{array}$ & Likert \\
\hline & $\begin{array}{l}\text { Commitment } \\
\text { (komitmen) }\end{array}$ & $\begin{array}{c}\text { Pekerja } \\
\text { mengikat } \\
\text { dengan } \\
\text { organisasi } \\
\text { dan } \\
\text { menunjukkan } \\
\text { tindakan } \\
\text { organizational } \\
\text { citizenship }\end{array}$ & Likert \\
\hline & $\begin{array}{c}\text { Statisfaction } \\
\text { (kepuasan) }\end{array}$ & $\begin{array}{c}\text { refleksi } \\
\text { pemenuhan } \\
\text { kontrak } \\
\text { psikologis } \\
\text { dan } \\
\text { memenuhi } \\
\text { harapan } \\
\text { ditempat } \\
\text { kerja. }\end{array}$ & Likert \\
\hline & $\begin{array}{c}\text { Turnover } \\
\text { (pergantian) }\end{array}$ & $\begin{array}{c}\text { kehilangan } \\
\text { pekerja yang } \\
\text { dihargai }\end{array}$ & Likert \\
\hline
\end{tabular}

\begin{tabular}{|c|c|c|c|}
\hline Variabel & Indikator & Instrumen & Skala \\
\hline \multirow{4}{*}{$\begin{array}{c}\text { Kinerja } \\
\text { Karyawan } \\
\text { (Sumber: } \\
\text { Mangkune } \\
\text { gara, 2009) }\end{array}$} & $\begin{array}{c}\text { Kualitas } \\
\text { Kerja }\end{array}$ & $\begin{array}{c}\text { Kualitas sesuai } \\
\text { harapan }\end{array}$ & Likert \\
\hline & $\begin{array}{c}\text { Kuantitas } \\
\text { kerja }\end{array}$ & $\begin{array}{c}\text { Petugas } \\
\text { mampu } \\
\text { menyelesaikan } \\
\text { seluruh tugas }\end{array}$ & Likert \\
\hline & $\begin{array}{c}\text { Kreatifitas } \\
\text { Kerja }\end{array}$ & $\begin{array}{c}\text { Kreatif dan } \\
\text { inovatif dalam } \\
\text { bekerja }\end{array}$ & Likert \\
\hline & $\begin{array}{c}\text { Pengetahu } \\
\text { an Kerja }\end{array}$ & $\begin{array}{c}\text { Pengetahuan } \\
\text { terkait tugas } \\
\text { dan tanggung } \\
\text { jawabnya }\end{array}$ & Likert \\
\hline
\end{tabular}




\subsection{Hipotesis}

H0 : Tidak terdapat pengaruh kepribadian terhadap kinerja karyawan pada PT BPR Fajar Artha Makmur.

H1: Terdapat pengaruh kepribadian terhadap kinerja karyawan pada PT BPR Fajar Artha Makmur.

H0 : Tidak terdapat pengaruh motivasi terhadap kinerja karyawan PT BPR Fajar Artha Makmur.

$\mathrm{H} 2$ : Terdapat pengaruh motivasi terhadap kinerja karyawan PT BPR Fajar Artha Makmur.

H0 : Tidak dapat pengaruh kepribadian dan motivasi secara bersamaan terhadap kinerja karyawan PT BPR Fajar Artha Makmur.

H3 : Terdapat pengaruh kepribadian dan motivasi secara bersamaan terhadap kinerja karyawan PT BPR Fajar Artha Makmur.

\section{METODE PENELITIAN}

\subsection{Jenis Penelitian}

Penelitian ini bersifat kuantitatif kausal, karena menggunakan data yang memerlukan perhitungan dan menganalisis hubungan-hubungan antara satu variabel dengan variabel lainnya. Penelitian kausal menguji hubungan "sebab akibat".

\subsection{Variabel Penelitian}

Pada penelitian ini terdapat dua variabel yang berhubungan yaitu:

$$
\begin{aligned}
& \text { - Variable X1: Kepribadian } \\
& \text { - VariabelX2 : Motivasi } \\
& \text { - Variabel Y : Kinerja }
\end{aligned}
$$

\subsection{Objek Penelitian}

Objek penelitian adalah objek yang diteliti dan diterangkan secara rinci, dapat berupa lembaga, organisasi dan lain sebagainya. Dalam penelitian ini objeknya adalah karyawan tetap maupun kontrak PT BPR Fajar Artha Makmur.

\subsection{Populasi dan Sampel}

Populasi dalam penelitian ini adalah seluruh karyawan yang bekerja pada kantor PT BPR Fajar Artha Makmur pada bidang operasional yang berjumlah 50 orang. Berdasarkan penelitian ini karena jumlah populasinya tidak lebih besar dari 100 orang responden, maka penulis mengambil $100 \%$ jumlah populasinya yang ada di BPR Fajar Artha Makmur yaitu sebanyak 50 orang.

\subsection{Teknik Analisis Data}

Agar data yang telah dikumpulkan dari hasil survey di lapangan dapat bermanfaat, maka data harus diolah dan dianalisa, sehingga dapat digunakan untuk menginterpretasi dan digunakan sebagai dasar dalam pengambilan keputusan. Sebelum melakukan tahap analisis data (pengolahan data), maka terlebih dahulu dilakukan uji reliabilita dan uji validitas.

\subsection{Uji Validitas}

Uji validitas digunakan untuk mengukur sah atau valid tidaknya suatu kuesioner. Uji validitas dilakukan dengan melakukan korelasi antara masing-masing skor indikator dengan total skor variabel.

\subsection{Uji Reliabilitas}

Uji reliabilitas dimaksudkan untuk mengukur suatu kuesioner yang merupakan indikator dari variabel. Reabilitas diukur dengan uji statistik ronbach's alpha (a). Suatu variabel dikatakan reliable jika memberikan nilai cronbach;s alpha $>0,60$

\subsection{Uji Normalitas}

Uji normalitas dimaksudkan untuk mengetahui bahwa data yang terkumpul atau data yang diperoleh dari hasil kuesioner yang merupakan indikator variabel berdistribusi normal atau berdistribusi tidak normal. Uji normalitas dalam penelitian ini menggunakan metode 
P-P Plot Normality dengan menggunakan bantuan program SPSS 19.0.

\subsection{Uji Korelasi}

Analisa korelasi digunakan untuk mengetahui apakah ada hubungan antara dua variabel.

\subsection{Analisis Regresi Linier Berganda}

Analisis regresi linier adalah analisis yang digunakan untuk mengetahui pengaruh antara beberapa variabel independen (X) yang dinyatakan dengan rumus (Sugiyono:2006). Rumus dari regresi linier adalah sebagai berikut:

$$
\mathbf{Y}=\mathbf{a}+\mathbf{b} 1 \mathbf{X} 1+\mathbf{b} 2 \mathbf{X} 2
$$

Dimana:

$$
\begin{aligned}
& \mathrm{Y}=\text { Kinerja pegawai } \\
& \mathrm{a}=\text { Nilai Konstanta } \\
& \mathrm{b} 1 \mathrm{~b} 2=\text { Koefisien Regresi } \\
& \mathrm{X} 1=\text { Kepribadian } \\
& \mathrm{X} 2=\text { Motivasi }
\end{aligned}
$$

\subsection{Uji Koefisien Determinasi}

Koefisien determinasi pada intinya mengukur seberapa jauh kemampuan model dalam menerangkan variasi variabel dependen. Nilai koefisien determinasi adalah antara nol dan satu. Nilai koefisien determinasi kecil, berarti kemampuan variabel-variabel independen dalam menjelaskan variasi variabel-variabel dependen sangat terbatas. Nilai koefesien determinasi mendekati satu, berarti kemampuan variabel-variabel independen memberikan hampir semua informasi yang dibutuhkan untuk memprediksi variasi variabel-variabel dependen (Ghozali,2005). Rumus koefisien determinasi adalah: $\mathrm{R}^{2}=($

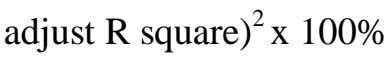

\subsection{Uji Hipotesis}

\section{a. Uji t}

Menurut Ghozali (2013) uji t pada dasarnya menunjukkan seberapa jauh pengaruh variabel independen secara individual dalam menerangkan variasi pada variabel dependen. Apabila pada taraf signifikansi diperoleh nilai probabilitas < 0,05, maka hipotesis diterima. Hal ini berarti ada pengaruh antara variabel dependen dengan variabel independen yang diuji. Sebaliknya, bila diperoleh nilaoi probabilitas > 0,05 maka hipotesis ditolak karena tidak ada pengaruh antara dua variabel yang diuji tersebut.

\section{b. Uji F}

Uji f pada dasarnya untuk menunjukkan seberapa jauh pengaruh seluruh variabel bebas secara bersama-sama dalam menerangkan variasi variabel terikatnya (Ghozali, 2013). Pengujian melalui uji $f$ dilakukan dengan menggunakan nilai sig (probability significancy). Koefisiensi regresi variabel bebas dinyatakan signifikan pengaruhnya terhadap variabel terikat apabila nilai sig (probability significancy) yang diperoleh lebih kecil dari tingkat kesalahan (alpha) yang telah ditentukan yaitu sebesar 5\% $(0,05)$.

\section{HASIL DAN PEMBAHASAN}

\subsection{Hasil Penelitian}

Deskripsi data yang akan disajikan dari hasil penelitian ini adalah untuk memberikan gambaran secara umum mengenai penyebaran data yang diperoleh dilapangan. Data yang disajikan berupa data mentah yang diolah menggunakan teknik statistik deskripsi. Deskripsi tersebut berguna untuk menjelaskan kecenderungan tengah, untuk menjelaskan pola penyebaran. Data yang digunakan pada penelitian ini terdiri dari 3 variabel yaitu tentang kepribadian (X1), motivasi (X2), dan kinerja (Y). Data tersebut diperoleh melalui kuesioner.

\subsection{Karakteristik Responden}

Karakteristik responden merupakan gambaran umum tentang keadaan karakteristik responden yang menjadi perumusan. Adapun karakteristik dalam 
penelitian ini didasarkan oleh jenis kelamin, usia, dan lama bekerja. Dengan mengambil responden yang berjumlah 50 orang sebagai sampel penelitian.

Tabel 4.2.1 Karakteristik responden berdasarkan jenis kelamin karyawan PT BPR Fajar Artha Makmur

\begin{tabular}{|c|l|c|c|}
\hline NO & \multicolumn{1}{|c|}{$\begin{array}{c}\text { JENIS } \\
\text { KELAMIN }\end{array}$} & JUMLAH & $\begin{array}{c}\text { PERSENTASE } \\
\%\end{array}$ \\
\hline 1. & Perempuan & 23 & $46 \%$ \\
\hline 2. & Laki-laki & 27 & $54 \%$ \\
\hline & Jumlah & $\mathbf{5 0}$ & $\mathbf{1 0 0}$ \\
\hline
\end{tabular}

Sumber: data primer yang diolah, 2018

Tabel 4.2.2 Karakteristik responden berdasarkan usia karyawan PT BPR Fajar Artha Makmur

\begin{tabular}{|c|c|c|c|}
\hline NO & USIA & JUMLAH & $\begin{array}{c}\text { PERSENTASE } \\
(\%)\end{array}$ \\
\hline 1. & $<25$ tahun & 16 & $32 \%$ \\
\hline 2. & $25-35$ tahun & 15 & $30 \%$ \\
\hline 3. & $36-45$ tahun & 12 & $24 \%$ \\
\hline 4. & $>46$ tahun & 7 & $14 \%$ \\
\hline & Jumlah & $\mathbf{5 0}$ & $\mathbf{1 0 0}$ \\
\hline
\end{tabular}

Tabel 4.2.3 Karakteristik responden berdasarkan pendidikan karyawan PT BPR Fajar Artha Makmur

\begin{tabular}{|c|c|c|c|}
\hline NO & PENDIDIKAN & $\begin{array}{c}\text { JUMLA } \\
\mathrm{H}\end{array}$ & $\begin{array}{c}\text { PERSENTASE } \\
(\%)\end{array}$ \\
\hline 1. & SMA & 6 & $12 \%$ \\
\hline 2. & Diploma (D1-D3) & 12 & $24 \%$ \\
\hline 3. & Sarjana & 29 & $58 \%$ \\
\hline 4. & Pasca Sarjana & 3 & $6 \%$ \\
\hline & Jumlah & $\mathbf{5 0}$ & $\mathbf{1 0 0}$ \\
\hline
\end{tabular}

Tabel 4.2.4 Karakteristik responden berdasarkan lama bekerja karyawan di PT BPR Fajar Artha Makmur

\begin{tabular}{|c|c|c|c|}
\hline NO & LAMA BEKEJA & JUMLAH & $\begin{array}{c}\text { PERSENT } \\
\text { ASE }(\%)\end{array}$ \\
\hline 1. & $<5$ tahun & 28 & $56 \%$ \\
\hline 2. & $6-15$ tahun & 22 & $44 \%$ \\
\hline 3. & $16-20$ tahun & 0 & $0 \%$ \\
\hline 4. & $>21$ tahun & 0 & $0 \%$ \\
\hline & Jumlah & $\mathbf{5 0}$ & $\mathbf{1 0 0}$ \\
\hline
\end{tabular}

Tabel 4.2.5 Karakteristik responden berdasarkan jabatan karyawan di PT BPR Fajar Artha Makmur

\begin{tabular}{|c|c|c|c|}
\hline NO & BAGIAN & JUMLAH & $\begin{array}{c}\text { PERSENTASE } \\
(\%)\end{array}$ \\
\hline 1. & Legal & 1 & $2 \%$ \\
\hline 2. & PE Kepatuhan & 2 & $4 \%$ \\
\hline 3. & Internal Control & 3 & $6 \%$ \\
\hline 4. & PE APU PPT & 3 & $6 \%$ \\
\hline 5. & Admin Kredit & 4 & $8 \%$ \\
\hline 6. & Kepala Bagian & 4 & $8 \%$ \\
\hline 7. & Account Officer & 12 & $24 \%$ \\
\hline 8. & Collector & 11 & $22 \%$ \\
\hline 9. & $\begin{array}{c}\text { Customer } \\
\text { Service }\end{array}$ & 3 & $6 \%$ \\
\hline 10. & Teller & 3 & $6 \%$ \\
\hline 11. & Akunting & 2 & $4 \%$ \\
\hline 12. & $\begin{array}{c}\text { Cleaning } \\
\text { Service }\end{array}$ & 2 & $4 \%$ \\
\hline & Jumlah & $\mathbf{5 0}$ & $\mathbf{1 0 0}$ \\
\hline
\end{tabular}

\subsection{Uji Validitas}

4.3.1 Hasil Pengujian Validitas Variabel Kepribadian (X1

\begin{tabular}{|c|c|c|c|}
\hline $\begin{array}{c}\text { No } \\
\text { pernyataan }\end{array}$ & R Hitung & $\begin{array}{c}\mathbf{R} \\
\text { Tabel }\end{array}$ & Keterangan \\
\hline $\mathrm{X} 11$ & 0,621 & 0,238 & Valid \\
\hline $\mathrm{X} 12$ & 0,718 & 0,238 & Valid \\
\hline $\mathrm{X} 13$ & 0,616 & 0,238 & Valid \\
\hline $\mathrm{X} 14$ & 0,307 & 0,238 & Valid \\
\hline $\mathrm{X} 15$ & 0,679 & 0,238 & Valid \\
\hline $\mathrm{X} 16$ & 0,847 & 0,238 & Valid \\
\hline $\mathrm{X} 17$ & 0,735 & 0,238 & Valid \\
\hline $\mathrm{X} 18$ & 0,768 & 0,238 & Valid \\
\hline $\mathrm{X} 19$ & 0,721 & 0,238 & Valid \\
\hline $\mathrm{X} 110$ & 0,750 & 0,238 & Valid \\
\hline
\end{tabular}

4.3.2 Hasil Pengujian Validitas Variabel Motivasi (X2)

\begin{tabular}{|c|c|c|c|}
\hline $\begin{array}{c}\text { No } \\
\text { pernyataan }\end{array}$ & $\begin{array}{c}\mathbf{R} \\
\text { Hitung }\end{array}$ & $\begin{array}{c}\mathbf{R} \\
\text { Tabel }\end{array}$ & Keterangan \\
\hline $\mathrm{X} 21$ & 0,317 & 0,238 & Valid \\
\hline $\mathrm{X} 22$ & 0,360 & 0,238 & Valid \\
\hline $\mathrm{X} 23$ & 0,396 & 0,238 & Valid \\
\hline $\mathrm{X} 24$ & 0,347 & 0,238 & Valid \\
\hline $\mathrm{X} 25$ & 0,501 & 0,238 & Valid \\
\hline $\mathrm{X} 26$ & 0,445 & 0,238 & Valid \\
\hline
\end{tabular}




\begin{tabular}{|c|c|c|c|}
\hline X27 & 0,409 & 0,28 & Valid \\
\hline X28 & 0,354 & 0,238 & Valid \\
\hline
\end{tabular}

Sumber : data primer yang telah diolah dengan SPSS 22.0

\subsubsection{Pengujian Validitas Variabel}

Kinerja (Y)

\begin{tabular}{|c|c|c|c|}
\hline $\begin{array}{c}\text { No } \\
\text { pernyataa } \\
\mathbf{n}\end{array}$ & $\begin{array}{c}\mathbf{R} \\
\text { Hitun } \\
\mathbf{g}\end{array}$ & $\begin{array}{c}\mathbf{R} \\
\text { Tabe } \\
\mathbf{l}\end{array}$ & $\begin{array}{c}\text { Keteranga } \\
\mathbf{n}\end{array}$ \\
\hline Y1 & 0,713 & 0,238 & Valid \\
\hline Y2 & 0,479 & 0,238 & Valid \\
\hline Y3 & 0,592 & 0,238 & Valid \\
\hline Y4 & 0,557 & 0,238 & Valid \\
\hline Y5 & 0,568 & 0,238 & Valid \\
\hline Y6 & 0,645 & 0,238 & Valid \\
\hline Y7 & 0,359 & 0,238 & Valid \\
\hline Y8 & 0,679 & 0,238 & Valid \\
\hline
\end{tabular}

Sumber : data primer yang telah diolah dengan SPSS 22.0

\subsection{Uji Reliabilitas}

\subsubsection{Tabel Uji Reliabilitas Variabel} Kepribadian

\begin{tabular}{|r|r|}
\hline \multicolumn{2}{|c|}{ Reliability Statistics } \\
\hline $\begin{array}{c}\text { Cronbach's } \\
\text { Alpha }\end{array}$ & N of Items \\
\hline, 864 & 10 \\
\hline
\end{tabular}

Sumber : Data diolah dengan Spss 22.0

\subsubsection{Uji Reliabilitas Variabel Motivasi}

\begin{tabular}{|r|r|}
\hline \multicolumn{2}{|c|}{ Reliability Statistics } \\
\hline $\begin{array}{c}\text { Cronbach's } \\
\text { Alpha }\end{array}$ & N of Items \\
\hline, 859 & 8 \\
\hline
\end{tabular}

Sumber : Data diolah dengan Spss 22.0

\subsubsection{Uji Reliabilitas Variabel Kinerja}

\begin{tabular}{|c|c|}
\hline \multicolumn{2}{|c|}{ Reliability Statistics } \\
\hline $\begin{array}{c}\text { Cronbach's } \\
\text { Alpha }\end{array}$ & N of Items \\
\hline, 715 & 8 \\
\hline
\end{tabular}

Sumber : Data diolah dengan Spss 22.0

\subsection{Uji Normalitas}

\subsubsection{Tabel Uji Normalitas}

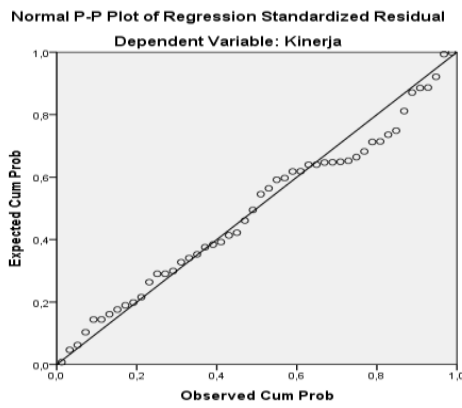

Sumber : Data diolah dengan Spss 22.0

\subsection{Analisis Regresi Berganda}

Pembuatan persamaan regresi dapat dilakukan dengan mempinterpretasikan angka-angka yang ada di dalam unstandardized coefficient beta. Berikut hasil table uji spss versi 22 dengan variabel independen kepribadian dan motivasi terhadap kinerja.

\subsubsection{Tabel Analisis Regresi Berganda} Analisis Regresi Berganda

\begin{tabular}{|c|c|c|c|c|c|c|}
\hline \multicolumn{7}{|c|}{ Coefficients $^{\mathrm{a}}$} \\
\hline & \multirow[t]{2}{*}{ Model } & \multicolumn{2}{|c|}{$\begin{array}{l}\text { Unstandardiz } \\
\text { ed } \\
\text { Coefficients }\end{array}$} & $\begin{array}{l}\text { Standar } \\
\text { dized } \\
\text { Coeffic } \\
\text { ients }\end{array}$ & \multirow[t]{2}{*}{$\mathrm{T}$} & \multirow[t]{2}{*}{ Sig. } \\
\hline & & B & $\begin{array}{l}\text { Std. } \\
\text { Error }\end{array}$ & Beta & & \\
\hline \multirow{3}{*}{1} & $\begin{array}{c}\text { (Consta } \\
\text { nt) }\end{array}$ & $\begin{array}{l}12, \\
685\end{array}$ & 3,218 & & 3,942 & ,000 \\
\hline & $\begin{array}{c}\text { Kepriba } \\
\text { dian }\end{array}$ & $\begin{array}{c}, 52 \\
3\end{array}$ & ,058 & ,790 & 8,969 & ,000 \\
\hline & $\begin{array}{c}\text { Motivas } \\
\text { i }\end{array}$ & $\begin{array}{c}05 \\
5\end{array}$ & ,059 & ,083 & ,945 & ,349 \\
\hline
\end{tabular}

Sumber : Data diolah dengan Spss 22.0

Dari hasil analisis data pada tabel tersebut, dapat diketahui persamaan regresinya, yaitu:

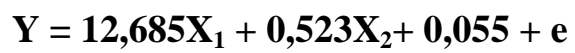

Nilai koefisien regresi dari variabel diatas menunjukkan besarnya pengaruh variabel bebas terhadap variabel terikat. Semakin besar nilai koefision variabel bebas (X), maka semakin besar pula pengaruhnya terhadap variabel terikat (Y). Interpretasi dari regresi linier:

1. $\mathrm{Y}=$ konstanta $=12,685$ artinya apabila kinerja karyawan PT BPR Fajar Artha 
Makmur tidak dipengaruhi oleh kepribadian dan motivasi maka kinerja tetap sebesar 12,685. Hal ini dapat disimpulkan bahwa kinerja karyawan PT BPR Fajar Atha Makmur tidak hanya dipengaruhi kepribadian dan motivasi saja, tetapi masih banyak faktor-faktor yang mempengaruhinya.

2. $\mathrm{b} 1=0,523$ merupakan koefisien arah variabel kepribadian (X1) yang mempengaruhi kinerja karyawan PT BPR Fajar Artha Makmur (Y), koefisien regresi (b1) sebesar 0,523 dengan tanda positif. Berarti bahwa apabila kepribadian dinaikkan sebesar satu satuan, maka kinerja petugas (Y) akan meningkat sebesar 0,523 . Sifat hubungan yang positif tersebut diartikan bahwa semakin baik kepribadian (X1), maka akan berpengaruh positif terhadap kinerja karyawan PT BPR Fajar Artha Makmur.

3. $\mathrm{b} 2=0,055$ merupakan koefisien arah variabel motivasi (X2) yang mempengaruhi kinerja karyawan PT BPR Fajar Artha Makmur (Y). Koefisien regresi (b2) sebesar 0,055 dengan tanda positif. Berarti bahwa apabila motivasi dinaikkan sebesa satu satuan, maka kinerja akan meningkat sebesar 0,055. Sifat hubungan yang positif tersebut dapat diartikan bahwa semakin baik motivasi, maka akan berpengaruh positif terhadap kinerja karyawan PT BPR Fajar Artha Makmur.

\subsection{Uji Korelasi Berganda}

Uji korelasi berganda bertujuan untuk mengetahui tingkat keeratan hubungan (simultan) antara dua atau lebih variabel bebas (X) terhadap variabel (Y). Adapun hasil pengolahan data dengan program SPSS versi 22, yaitu sebagai berikut:
4.7.1 Tabel Hasil Analisis Koefisien Korelasi

\begin{tabular}{|l|c|c|l|l|}
\hline \multicolumn{5}{|c|}{ Model Summary } \\
\hline Model & $\mathrm{R}$ & $\begin{array}{c}\mathrm{R} \\
\text { Square }\end{array}$ & $\begin{array}{c}\text { Adjusted R } \\
\text { Square }\end{array}$ & $\begin{array}{c}\text { Std. Error of the } \\
\text { Estimate }\end{array}$ \\
\hline 1 & $797^{\mathrm{a}}$ & .635 & .620 & 2.20112 \\
\hline \multicolumn{3}{|c|}{ a. Predictors: (Constant), Motivasi, Kepribadian (X) } \\
\hline \multicolumn{2}{|l|}{ b. Dependent Variabel: Kinerja }
\end{tabular}

Sumber : Data diolah dengan Spss 22.0

Berdasarkan tabel di atas, diperoleh nilai koefisien $\mathrm{R}^{2}$ adjusted sebesar 0,62 , dan sesuai dengan ketentuan penulis, maka dapat disimpulkan bahwa variabel (X) memiliki tingkat kekuatan hubungan yang kuat terhadap variabel kinerja karyawan (Y).

\subsection{Uji Koefisien Determinasi $R$}

Analisis koefisien determinasi dipergunakan untuk mengukur besarnya pengaruh variabel kepribadian dan motivasi terhadap kinerja karyawan pada PT BPR Fajar Artha Makmur. Determinasi dihitung dengan menggunakan rumus : $\mathrm{KD}=\mathrm{R}^{2} \mathrm{x}$ $100 \%$. Berikut ini hasil perhitungan koefisien determinasi yang diolah dengan program SPSS versi 20, terlihat pada tabel bawah ini:

4.8.1 Tabel Hasil Analisis Koefisien Determinasi $\mathbf{R}$

\begin{tabular}{|c|c|c|c|c|}
\hline \multicolumn{5}{|c|}{ Model Summary } \\
\hline $\begin{array}{c}\text { Mod } \\
\text { el }\end{array}$ & $\mathrm{R}$ & $\begin{array}{c}\mathrm{R} \\
\text { Square }\end{array}$ & $\begin{array}{l}\text { Adjusted } \\
\text { R Square }\end{array}$ & $\begin{array}{l}\text { Std. Error of the } \\
\text { Estimate }\end{array}$ \\
\hline 1 & $.797^{\mathrm{a}}$ & .635 & .620 & 2.20112 \\
\hline \multicolumn{5}{|c|}{ a. Predictors: (Constant), Motivasi, Kepribadian (X) } \\
\hline \multicolumn{5}{|c|}{ b. Dependent Variabel: Kinerja } \\
\hline
\end{tabular}

Berdasarkan hasil olah data menggunakan spss didapatkan nilai koefisien determinasi $\mathrm{R}$ adjusted sebesar 0.62 hal ini menunjukkan bahwa sebesar variabel kepribadian dan motivasi (X) berpengaruh terhadap variabel kinerja 
karyawan (Y) sebesar 62\%. sedangkan sisanya $38, \%$ dipengaruhi oleh faktor lain.

\subsection{Uji Hipotesis}

\subsubsection{Tabel Pengujian hipotesis dengan} uji t

\begin{tabular}{|c|c|c|c|c|c|c|}
\hline \multicolumn{7}{|c|}{ Coefficients $^{\mathrm{a}}$} \\
\hline & \multirow{2}{*}{ Model } & \multicolumn{2}{|c|}{$\begin{array}{l}\text { Unstandardize } \\
\text { d Coefficients }\end{array}$} & \multirow{2}{*}{ 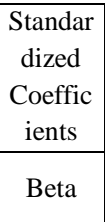 } & \multirow{2}{*}{$\mathrm{T}$} & \multirow{2}{*}{ Sig } \\
\hline & & B & $\begin{array}{l}\text { Std. } \\
\text { Error }\end{array}$ & & & \\
\hline \multirow{3}{*}{1} & (Constant) & 12,685 & 3,218 & & 3,942 & ,000 \\
\hline & $\begin{array}{c}\text { Kepribadia } \\
n\end{array}$ & ,523 & ,058 & ,790 & 8,969 & ,000 \\
\hline & Motivasi & 055 & ,059 & ,083 & ,945 &, 349 \\
\hline
\end{tabular}

Sumber : Data diolah dengan Spss 22.0

Dari tabel diatas untk menguji keberartian model regresi untuk masingmasing variabel secara persial dapat diperoleh dengan menggunakan uji t. Berikut akan dijelaskan pengujian masingmasing variabel secara parsial, antara lain:

1. Variabel Kepribadian

Hasil pengujian diperoleh nilai t hitung untuk variabel kepribadian menunjukkan nilai $\mathrm{t}$ hitung $=8,969$. Nilai $\mathrm{t}$ tabel dengan $\mathrm{df}=\mathrm{n}-\mathrm{k}-1=50-2-1$ $=47$ dengan diperoleh nilai $\mathrm{t}$ sebesar 1.677. Dengan demikian diperoleh $\mathrm{t}$ hitung $(8,969)>t$ tabel $(1,677)$, sehingga dapat disimpulkan bahwa $\mathrm{H} 1$ diterima yang berarti terdapat pengaruh kepribadian terhadap kinerja.

2. Variabel Motivasi

Hasil pengujian diperoleh nilai t hitung untuk variabel motivasi menunjukkan nilai $\mathrm{t}$ hitung $=1,780$. Nilai $\mathrm{t}$ tabel dengan $\mathrm{df}=\mathrm{n}-\mathrm{k}-1=50-2-1=47$ dengan diperoleh nilai t sebesar 1,677. Dengan demikian diperoleh $\mathrm{t}$ hitung $(0,945)<(1,677)$, sehingga dapat disimpulkan bahwa $\mathrm{H} 2$ ditolak yang berarti tidak terdapat pengaruh motivasi terhadap kinerja.
4.9.2 Tabel Pengujian hipotesis dengan uji F

\begin{tabular}{|c|c|c|c|c|c|c|}
\hline \multicolumn{7}{|c|}{ ANOVA $^{\mathrm{a}}$} \\
\hline \multicolumn{2}{|c|}{ Model } & $\begin{array}{c}\text { Sum of } \\
\text { Squares }\end{array}$ & $\begin{array}{c}\text { D } \\
\text { f }\end{array}$ & $\begin{array}{c}\text { Mean } \\
\text { Square }\end{array}$ & F & Sig. \\
\hline \multirow{4}{*}{1} & $\begin{array}{c}\text { Regressio } \\
\text { n }\end{array}$ & 396,609 & 2 & $\begin{array}{c}198,30 \\
4\end{array}$ & $\begin{array}{c}40, \\
93 \\
0\end{array}$ &, $000^{\mathrm{b}}$ \\
\cline { 2 - 7 } & Residual & 227,711 & 4 & 4,845 & & \\
\cline { 2 - 7 } & Total & 624,320 & $\begin{array}{c}4 \\
9\end{array}$ & & & \\
\cline { 2 - 7 } & \multicolumn{6}{|c|}{ a. Dependent Variable: Kinerja } \\
\hline \multicolumn{6}{|c|}{ b. Predictors: (Constant), Motivasi, Kedisiplinan } \\
\hline
\end{tabular}

Sumber : Data diolah dengan Spss 22.0

Pengujian pengaruh variabel bebas secara bersama-sama terhadap variabel terikatnya dilakukan dengan menggunakan uji F. Hasil perhitungan statistik menunjukkan nilai $\mathrm{F}$ hitung 40,90 dengan signifikan $0,000<0,05$. Nilai $F$ tabel dengan $\mathrm{df}=\mathrm{n}-\mathrm{k}-1=50-2-1=47$ diperoleh sebesar 2,80. Dengan demikian nilai $F$ hitung $=(40,930)$ lebih besar dari $F$ tabel $(2,80)$, sehingga dapat disimpulkan bahwa H3 diterima yang berarti terdapat pengaruh kepribadian dan motivasi secara simultan terhadap kinerja.

\section{KESIMPULAN DAN SARAN}

\subsection{Kesimpulan}

Berdasarkan hasil analisis deskriptip terhadap penelitian yang telah penulis lakukan yaitu mengenai kedisiplinan dan motivasi terhadap pengaruh kinerja karyawan pada PT. BPR Fajar Artha Makmur dengan mengacu kepada hasil analisis koefisien korelasi untuk mengetahui seberapa besar pengaruh kedisiplinan dan motivasi terhadap kinerja karyawan pada PT. BPR Fajar Artha Makmur, maka dapat diambil kesimpulan sebagai berikut:

1. Disiplin pada PT. BPR Fajar Artha Makmur telah berjalan sangat baik. Hal ini terlihat berdasarkan hasil jawaban dari responden sebanyak 50 
orang, dengan jumlah rata-rata sebesar 3,82 .

2. Motivasi pada PT. BPR Fajar Artha Makmur telah berjalan cukup baik. Hal ini terlihat berdasarkan hasil jawaban dari responden sebanyak 50 orang, dengan jumlah rata-rata sebesar 3,02.

3. Berdasarkan hasil analisis data dengan menggunakan metode statistik yaitu koefisien korelasi yaitu sebesar 0,797, dan sesuai dengan ketentuan penulis, maka dapat disimpulkan bahwa kedisiplinan dan motivasi memiliki tingkat kekuatan hubungan yang kuat terhadap variabel kinerja karyawan, hal ini menunjukkan bahwa kedisiplinan dan motivasi berpengaruh kuat terhadap kinerja karyawan pada PT. BPR Fajar Artha Makmur.

\subsection{Saran}

Berdasarkan hasil temuan dari penelitian ini, penulis mengemukakan saran yang berkaitan dengan kedisiplinan, motivasi dan kinerja karyawan pada PT. BPR Fajar Artha Makmur diantaranya adalah:

1. Manajemen PT. BPR Fajar Artha Makmur agar terus meningkatkan disiplin kerja karyawannya dengan melakukan pengawasan yang ketat agar karyawan lebih disiplin mmematuhi peraturan perusahaan.

2. Manajemen PT. BPR Fajar Artha Makmur agar terus meningkatkan halhal yang harus memotivasi karyawannya, agar karyawan selalu termotivasi dalam melakukan setiap tugas dan tanggung jawabnya.

3. Tindakan tegas terhadap karyawan yang kurang disiplin harus dilakukan sehingga kinerja karyawan tersebut meningkat.

\section{DAFTAR PUSTAKA}

Arikunto. 2014. "Penelitian Tindakan Kelas”. Jakarta: PT. Bumi Aksara.

Ghozali. 2005. "Aplikasi Analisis Multivariate dengan SPSS”. Semarang: Universitas Diponegoro.

Ghozali. 2013. "Aplikasi Analisis Multivariate dengan Program IBM SPSS 21 Update PLS Regresi”. Semarang: Universitas Diponegoro.

Gomes, C. Faustino. 2000. "Manajemen Sumber Daya Manusia”. Bandung: PT. Remaja Rosdakarya.

Hadari, H. Nawawi. 1997. "Manajemen Sumber Daya Manusia”. Yogyakarta. Gajah Mada University Press.

Heller, R. 1998. "Perilaku Dalam Organisasi”. Edisi Kedua. PT. Rajagrafindo Persada.

Judge \& Robbins. 2010. "Perilaku Dalam Organisasi”. Edisi Kedua. PT. Rajagrafindo Persada.

Siagian. 2004. “ Manajemen Sumber Daya Manusia”. Jakarta: PT. Bumi Aksara.

Sugiyono. 2002. "Metode Penelititan Administrasi". Bandung: Alfabeta.

Sugiyono. 2006. "Metode Penelitian Kuantitatif, Kualitatif dan R \& D”. Bandung: Alfabeta.

Sugiyono.2010. "Statiska Untuk Penelitian”. Bandung: Alfabet.

Sugiyono.2014. "Metode Penelitian Pendidikan Pendekatan Kualitatif'. Bandung. CV. Alfabeta.

Von Glino \& McShane. 2010. "Perilaku Dalam Organisasi”. Edisi Kedua. PT. Rajagrafindo Persada.

Wesson. Lepine \& Colquitt. 2011. "Perilaku Dalam Organisasi". Edisi Kedua. PT. Rajagrafindo Persada.

Wilson, B. 2012. "Manajemen Sumber Daya Manusia". Jakarta: Erlangga.

http://repository.umy.ac.id/bitstream/handle /123456789/6200/G.\%20BAB\%20III.p df? sequence $=7 \&$ is Allowed $=y$ 